Short title running head: DDT AND UROGENITAL MALFORMATIONS IN NEWBORN BOYS IN A MALARIAL AREA

Authors running head: Bornman et al.

Accepted for publication 13 August 2009

\section{DDT and urogenital malformations in newborn boys in a malarial area}

\author{
Riana Bornman, Christiaan de Jager*, Zeleke \\ Worku**, Paulina Farias $†$ and Simon Reif \\ Department of Urology and *School of Health Systems and \\ Public Health, University of Pretoria, Pretoria, South \\ Africa, ** Department of Statistics, University of South \\ Africa, Pretoria, South Africa and †Instituto Nacional De \\ Salud Publica, Ahuacatitlan Cuernavaca, Morelos, Mexico
}

\begin{abstract}
Objective To determine the risk of external urogenital birth defects (UGBDs) in newborn boys from a malarial area currently sprayed with technical DDT, 1,1,1-trichloro-2,2bis(4-chlorophenyl) ethane (DDT), as increased fetal oestrogenic or anti-androgenic exposure might be involved in the pathogenesis of increased prevalence of human male reproductive tract anomalies, and DDT and metabolites interact with both these receptors.

Subjects and methods We examined 3310 newborn baby boys and recorded external UGBDs.

Results Of the newborn boys 10.8\% (357) had UGBDs; a multivariate logistic model showed that mothers who lived in villages sprayed with DDT between 1995 and 2003 had a significantly greater chance (33\%) of having a baby with a UGBD than mothers whose homes were not sprayed (odds ratio 1.33 , 95\% confidence interval 1.04-1.72). Being a homemaker instead of being employed further significantly increased the risk of having a baby with a UGBD by $41 \%$ (odds ratio 1.41, 1.13-1.77).

Conclusions Maternal exposure to DDT by living in a DDTsprayed village was associated to having male offspring with one or more UGBDs. Monitoring the impact of indoor residual spraying on human and environmental health is imperative if DDT is being used, especially as climate change raises concerns about the global spread of malaria. Integrating adequate indoor residual spraying measures by malarial vector control programmes, and increased public awareness to limit personal exposure, are crucial components that need to be addressed.
\end{abstract}

Keywords epidemiology, indoor residual spraying, malaria, newborns, testicular dysgenesis syndrome, DDT

\section{Introduction}

Cryptorchidism and hypospadias are part of the testicular dysgenesis syndrome (TDS), which includes other male reproductive disorders such as testicular cancer and decreased semen quality, possibly with a shared pathogenesis. TDS has been shown in animals and proposed for humans. Skakkebaek et al. [1] suggested that prenatal exposure to endocrine disruptors might lead to increased rates of cryptorchidism, hypospadias, testicular cancer and as infertility. Aitken et al. [2] indicated that oestrogenicity of a compound might not be the only determinant of developmental defects [3]. This was confirmed by Fisher [4] who showed that anti-androgenic chemicals, inhibitors of steroidogenic pathways, and oestrogens or anti-oestrogens, are also associated with the TDS.

Although endocrine disrupters are considered prime candidates of environmental influence on the development of TDS in humans [5], human evidence of a link between endocrine-disrupting chemical exposure and TDS remains difficult to confirm. However, one opportunity to more closely investigate such a connection might be human populations living in areas where malaria still occurs and technical DDT is used for malarial vector control. Although most countries have banned the use of DDT, certain endemic malarial areas still have to use indoor residual spraying (IRS) with DDT to decrease the incidence and spread of the disease, by controlling mosquitoes [6]. One such area is the Vhembe District Municipality of Limpopo Province, in the north-eastern corner of South Africa, bordering Zimbabwe and Mozambique (Fig. 1), where the highest incidence rate of malaria cases in Limpopo Province occurred between 1998 and 2007 [7]. Most people living here are from the Vhavenda tribe and of similar cultural and genetic backgrounds. DDT spraying was introduced in 1945 for malarial vector control, and since 1966 DDT has been sprayed annually (personal communication, P. Kruger, Limpopo Malaria Control Programme).

Technical DDT (the insecticide applied during IRS) is composed of $65-80 \%$ of the active insecticidal ingredient, 1,1,1-trichloro-2,2-bis(4-chlorophenyl) ethane ( $p, p$-DDT) and $15-21 \%$ of the less insecticidal 1,1,1-trichloro-2-(2chlorophenyl)-2-(4-chlorophenyl) ethane (o,p -DDT) [8]. Technical DDT has oestrogen-like properties, which is largely due to the $o, p$-DDT [9]. Environmental or dietary exposure to DDT and metabolites results in the bioaccumulation of these chemicals in the human body in adipose tissue, serum and breast milk [10-12]. DDT from the circulation is metabolized to the persistent metabolite $p, p$-DDE, which bio-accumulates in fatty tissue and it is a marker of chronic exposure to DDT [13].

$p, p$-DDE inhibits androgen binding to the androgen receptor, androgen-induced transcriptional activity, and normal male prepubertal development [14]. Danzo [15] reported that $p, p$-DDE was the most potent of the chemicals tested, but both $o, p$-DDT and $p, p$-DDT were also potent inhibitors. It has been estimated that if exposure would totally cease, it would take $10-20$ years for DDT to 
disappear from an individual [16], but that DDE would possibly persist throughout the full lifespan [10] as the halflife of plasma DDE is 10 years [17]. DDT and metabolites cross the placenta and the residue concentrations in cord blood are very similar to those in maternal blood, with $p, p$-DDE at the highest concentrations [18]. Studies conducted in other DDT-sprayed areas in South Africa also reported very high levels of DDT/E in breastmilk [12]. This implies that some of the DDT and DDE in a newborn baby could in fact have been transferred from the grandmother to the mother and then to the baby. The persistence and long half-life of these chemicals makes it crucial to also assess previous spraying with DDT, as the effect might become apparent after years of chronic low-dose exposure, and not necessarily after acute application.

In utero exposure of animals to DDT or DDE was associated with the development of ovarian tissue [19], reduced penis size in alligators [21], hypospadias and cryptorchidism [22]. It has been suggested that exposure to DDT might be involved in the increase in human male reproductive tract anomalies [3,14,22], but supportive data were lacking. Recently, Aneck-Hahn et al. [23] showed that healthy males living in a currently DDT-sprayed area had impaired semen quality. Plasma $p, p$-DDT and $p, p$-DDE values were statistically significantly higher in men living in DDT-sprayed houses than in men from unsprayed houses, suggesting that IRS could contribute to increased exposure to DDT and might have far reaching implications for reproductive and general health.

The objective of the present study was to determine the association of external urogenital birth defects (UGBDs) in newborn boys with DDT exposure from spraying in a malaria area.

\section{Subjects and methods}

This was a cross-sectional hospital-based study on UGBDs in newborn boys. The Human Ethics Committee of the University of Pretoria (44/2003), and the Department of Health and Social Development, Limpopo Government (0711-2002) granted permission. The Hospital Board of Tshilidzini Hospital, Thohoyandou, Limpopo Province consented access to the files of all full-term babies and allowed the project staff to examine babies and the record findings. Individual mothers gave oral informed consent before the examination.

The study area was in the Vhembe District Municipality of Limpopo Province, South Africa (Fig. 1). The villages included were around the city of Thohoyandou and the area east and north of Thohoyandou is a high-risk area for malaria [24].

Two retired professional nurses were trained by a specialist Paediatrician in the examination of newborns. They administered questionnaires, examined the babies and completed the data sheets. Mothers who resided outside Limpopo Province, who were private patients (not public patients), and babies with a birth mass of $<2.5 \mathrm{~kg}$ were excluded.
The questionnaire was devised so that responses provided demographic information, numbers, or 'yes' or 'no' answers. The birth mass and number of siblings was reported. Information on the mother included age, employment, smoking, alcohol intake, and ethnicity, and the village where the mother was residing. Information on possible consanguinity was also obtained, to assess any possible close genetic relationship between the mother and father. Using the names of the villages, the staff from the Malaria Control Programme provided information to classify the villages into currently DDT-sprayed and currently unsprayed villages. Participants were from 109 currently DDT-sprayed and 97 currently unsprayed villages.

In the newborn boys, the penis was inspected and ventral, lateral or dorsal congenital curvature of the phallus noted as chordee [25]. The flaccid stretched penile length was measured and, if $<1.9 \mathrm{~cm}$, recorded as micropenis [26]. Phimosis was noted when the foreskin had a white band preventing retraction of the foreskin to visualize the meatus. The position of the urethral meatus was inspected and hypospadias noted as an ectopic urethral meatus on the ventral aspect of the penis, scrotum or perineum. The scrotum was assessed for normal development, the gonads palpated and their position noted. Newborns were considered to have cryptorchidism if an undescended testicle (UDT) was found [27]. Babies with UGBDs were referred to the residing paediatricians for management. Anomalies were coded as definite if confirmed by a paediatrician or a genetics Nursing Specialist.

The study was done over a 2-year period from May 2004 to 2006, and 7146 newborns were examined. Files without information on the spray status of the village and the genital examination were excluded. Of the 6936 babies initially studied, 3518 were boys, 3393 were girls, 25 had ambiguous genitalia and the sex ratio was $51: 49$ (M : F). Baby boys whose birth mass was $<2.5 \mathrm{~kg}$ were excluded (208) total???.

We investigated the association of IRS with DDT and UGBDs in newborn boys. Assuming that at least some of these endpoints have a common cause due to endocrine alterations, and to increase the power, they were grouped as 'any UGBD' variable. All urogenital malformation variables were analysed as being either present or absent. Babies from a sprayed village were considered as DDT-exposed, and those from other villages as unexposed.

For maternal ethnicity, the Pedi, Tsonga and Venda were reported separately; the rest, being too few, were grouped as 'other ethnicity'. Maternal occupation was reported as homemakers (yes, no) and students (yes, no) and the rest grouped as 'employed' (yes, no). Other variables considered in the analysis were the mother's age and the time she had lived in the village (both in years), maternal smoking and drinking habits, parents' consanguinity (yes, no) and baby's birth mass and number of siblings. Maternal age was analysed as a continuous variable, but as it is not expected to have a linear association to birth defects, it was also categorized in three groups of 12-19, 20-34 and 3548 years. The number of siblings was included as possibly reflecting a means of DDT excretion through every previous 
birth. The association between each dependent variable (urogenital malformation) and each independent variable (DDT exposure in any of its forms, and other predictors) was analysed. In cases where fewer than five subjects where represented in any category, the association was not taken into account. Associations with a statistical significance of $P \quad 0.15$ were considered in multivariate logistic regression models. In a multivariate model, variables were excluded one at a time, starting with the least significant one. Only variables with $P<0.05$ or whose exclusion changed the other coefficients by $>10 \%$ were kept in the final model.

\section{Results}

Only four mothers reported smoking and seven drinking alcohol, so these variables were not considered any further. Table 1 summarizes the general characteristics of the mothers and their 3310 babies by DDT exposure (defined as ever been exposed vs never been exposed to DDT IRS). The mean (SD, range) age of all the mothers was $25.4(6.5,13-$ 48 ) years, and $68 \%$ of them were aged $20-34$ years. The mean (SD) duration of maternal residence in the current village was 22.7 (9) years. Consanguinity was reported in $3.6 \%$ of all mothers. The vast majority (91\%) of all the mothers were Venda, and the single largest category of occupation was being a homemaker (43\%), while $34 \%$ of them were attending school or further education.

The spray history of the various groups of villages is summarized in Table 2; 33.9\% (1122) subjects were from currently DDT-sprayed villages. Some subjects came from villages sprayed between 1995 and 2003, or between 1945 and 1979. No official information was available from 1980 to 1994 . Therefore, 2396 (72.4\%) women were from villages where DDT was sprayed at some time, while $27.6 \%$ of the women were from villages that were never sprayed.

The distribution of UGBDs in newborn boys by DDT spraying is shown in Table 3. Some malformations had a slightly higher percentage in places that had been sprayed with DDT than in from places that had never been sprayed. However, only a few of these differences were statistically significant (Table 4). For most malformations, the percentages of UGBDs were practically the same for both sprayed and never-sprayed. The wide CIs in most of the associations reflect the uncertainty due to the relatively few malformations in each compared group. Chordee and UDT were associated with the village having been sprayed, but only chordee had a significant association $(P=0.04)$.

Grouping the UGBDs as a single variable for male babies provided stronger associations. According to the final multivariable logistic model including 3144 male babies, mothers who lived in villages that were sprayed between 1995 and 2003 had a 33\% greater chance of having a baby with a UGBD than mothers whose homes were not sprayed during that time. This association was controlled for time residing in the village and for maternal occupation. Being a homemaker instead of being employed in any other activity significantly increased the risk of having a baby with a UGBD by $41 \%$. Although the time lived in the village was not quite statistically significant $(P=0.09)$ and was close to nil, it was kept in the model because of its influence on the exposure variable. Ethnicity, consanguinity and maternal age had no influence on the occurrence of UGBDs in this model.

\section{Discussion}

Living in a village that was sprayed with DDT 5-9 years before the study (1995-2003) was associated with a significantly greater risk of having a child with any UGBD by $33 \%$. The long half-life of DDT and DDE implies that even after discontinuing DDT for IRS, health effects might occur and any form of previous DDT exposure should therefore be accounted for in future studies. Moreover, being a homemaker was significantly associated with a greater risk of having a male child with a UGBD. It seems likely that these mothers spend more time indoors and could therefore be exposed more frequently and for longer periods to DDT used for IRS. The increased risk for homemakers is in accordance with various studies showing the possible adverse health effects associated with 'normal' residential exposure of pregnant women, including pre-term abortion, still birth, or shortened lactation [28,29]. The increased risk to homemakers also means that babies, infants and children might likewise be exposed indoors, albeit through different pathways. This indoor exposure has a significant effect, as Eskenazi et al. [30] reported that children exposed before the first 2 years of life are at greater risk of developing adverse health effects, such as delayed neurodevelopment. Taken together, the findings support the need for the assessment of indoor air and dust levels for DDT and metabolites after IRS.

In this study group, smoking and drinking alcohol were not sufficient in frequency to be a confounder. Even though we did not inquire about paternal smoking and drinking habits, other studies have shown that men from these villages seldom smoke or drink alcohol [23]. Therefore, parental smoking and drinking alcohol can probably be dismissed as risk factors for UGBDs in this population.

In this study, hypospadias occurred in $5.2 \%$ of newborn boys from this area, irrespective whether the mothers were living in sprayed and unsprayed villages, and hypospadias was not significantly associated with DDT exposure. However, the overall presence of hypospadias was higher than what is expected in 'normal' male newborns ( 1 in 250, 0.4\%) [31] and at least one order of magnitude higher than figures reported from the UK and Scandinavian countries [32]. In this study, hypospadias was reported in $6.87 / 1000$ live births, and the prevalence of glanular hypospadias were very high $(1.5 \%$ of newborns; data not shown). No previous study on UGBDs has been conducted in the Venda population, but the prevalence was lower in two other studies from South Africa (0.29/1000 live births [33] and 0.79/1000 live births [34], respectively). The subjects in these studies were from different ethnic groups and the hospital service areas fall outside the malarial areas. Although ethnic and regional differences might exist, the $>60$ years of continuous DDT exposure in the study area 
makes it almost unfeasible to consider any other possible causal or contributing factor without considering the possible effects of DDT. However, it is possible that some other unknown factor that differed between people in sprayed and unsprayed villages could account for some of the associations seen. The socio-economic status of the whole region is poor, with only a few small industries and no mining. Cooking and heating is by a combination of biomass burning and a little electricity, but with no noticeable differences between the sprayed and unsprayed villages. The unsprayed villages were located closer to commercial farming areas with intense pesticide use.

The Venda people originated from the Great Lakes of Central Africa and were one of the last groups to have migrated south of the Limpopo River. During the years of settlement, the Venda encouraged marriage between kin, especially with a cross-cousin [35], but over time this was relaxed to include a wider circle. In the present study, the mothers typically remain in a specific village, often where they were born, with very little movement between villages, as reflected by the long mean time residing in a specific village (22.7 years). As consanguinity was reported in $3.64 \%$ of the cases, the possible effect of inherited factors on the presence of UGBDs needs to be explored in more detail in follow-up studies. Interfamilial marriage was common in various ethnic groups throughout history and is today still practised in different groups [36]. To the best of our knowledge, a high prevalence of hypospadias and UGBDs in these populations has not been reported previously. Therefore, it is unlikely that in our case genetic transmissible factors alone would be the cause. The possibility that people living in this area constitute a vulnerable group with a higher susceptibility to the effect of exposure to various environmental factors, including chemical exposures, could likewise not be excluded.

The measurement of exposure in this study was a robust approximation of the real exposure scenario. The higher than expected prevalence of defects found in never-sprayed villages suggests that the measurement of exposure needs to be refined, such as by measuring serum levels of DDT and metabolites, although this would account for current and not variable historic levels of exposure. The findings also suggest that the development of UGBDs in baby boys might be influenced by maternal exposure to IRS of DDT during different stages of her life. These findings must be followed up by a case-control study with adequate numbers and consideration of other risk factors for UGBDs, to better evaluate an independent association of UGBDs with DDT and for clearer conclusions. This is particularly relevant since Longnecker et al. [27] reported, in the Collaborative Perinatal Project, odds ratios of 1.07 (95\% CI 0.97-1.18) for cryptorchidism (in 219 boys) and $1.01(0.90-1.14)$ for hypospadias (in 199) for each $2.67 \mu \mathrm{g} / \mathrm{g}$ lipids increase in maternal serum p,p -DDE. Although Longnecker et al. [37] found no reduced androgen action, as reflected by anogenital distance or penile dimensions at birth, in the newborn human males from Chiapas, México, the outcome in mothers from currently sprayed homes needs to be assessed.
Finally, the use of DDT has contributed to the success in reducing malarial transmission and malarial deaths in South and Southern Africa [38]. However, the present findings also strongly suggest that IRS with DDT is associated with UGBDs in newborn boys. If this association is causal, it should be accounted for in any future assessment of the costs and benefits of vector control with DDT. With the global concern about the effect of chemicals on health, and the possibility of malaria resurgence and spread as a result of climate change, all authorities should ensure that the general public, including those living under IRS conditions, are fully informed and aware of the possible health risks. Educating people living in the DDT-sprayed communities about ways to protect themselves from undue DDT exposure needs to be done as a matter of extreme urgency. There must be longterm monitoring of possible environmental and human health impacts [39], particularly in those areas where DDT will be introduced as part of the malaria campaign.

\section{Acknowledgements}

We received support from the Medical Research Council and the Urological Association Society of Southern Africa. We gratefully acknowledge the assistance of Mrr P. Kruger, Z. Radali and R. Mudzielwana (Malaria Control Programme), the Staff of Tshilidzini Hospital, Mss R. Mandiwana, L. Maela and K. Wannenburg. We thank Prof Henk Bouwman for comments on the manuscript. The authors declare they have no conflict of interest.

\section{References}

1 Skakkebæk NE, Rajpert-De Meyts E, Main KM. Testicular dysgenesis syndrome: an increasingly common developmental disorder with environmental aspects. Opinion Hum Reprod 2001; 16: 972-8

2 Aitken RJ, Koopman P, Lewis SEM. Seeds of concern. Nature 2004; 432: 48-52

3 Sharpe RM, Skakkebæk NE. Are estrogens involved in falling sperm counts and disorders of the male reproductive tract? Lancet 1993; 341: 1392-5

4 Fisher JS. Environmental anti-androgens and male reproductive health: focus on phthalates and testicular dysgenesis syndrome. Reproduction 2004; 127: 305-15

5 Virtanen HE, Rajpert-De Meyts E, Main KM, Skakkebæk NE, Toppari J. Testicular dysgenesis syndrome and the development and occurrence of male reproductive disorders. Toxicol Appl Pharm 2005; 207: S501-S505

6 Bouwman H. South Africa and the Stockholm Convention on Persistent Organic Pollutants. SA J Sci 2004; 100: 323-8

7 Gerritsen AM, Kruger P, Schim van der Loeff MF, Grobusch MP. Malaria incidence in Limpopo Province, South Africa, 1998-2007. Malaria J 2008; 7: 162

8 Bouwman H, Sereda B, Meinhardt HM. Simultaneous presence of DDT and pyrethroid residues in human breast milk from a malaria endemic area in South Africa. Environ Pollut 2006; 144: 902-17

9 Metcalf RL. Insect control technology. In Kroschwitz J, Howe-Grant $\mathrm{M}$, eds. Kirk-Othmer Encyclopedia of Chemical Technology, Vol. 14. New York, NY: John Wiley 
and Sons, Inc, 1995: 524-602

10 Smith AG. Chlorinated hydrocarbons. In Hayes WJ Jr, Edwards RL Jr eds. Handbook of Pesticide Toxicology, Vol. 2. New York: Academic Press, 1991: 731-90

11 Spear R. Recognized and possible exposure to pesticides. In Hayes WJ Jr, Edwards RL Jr eds. Handbook of Pesticide Toxicology, Vol. 1. New York: Academic Press, 1999: 24574

12 Bouwman H, Becker PJ, Schutte CH. Malaria control and longitudinal changes in levels of DDT and its metabolites in human serum from KwaZulu. Bull World Health Organ 1994; 72: 921-30

13 World Health Organization. Environmental Health Criteria No. 9. DDT and its derivatives. Geneva: UNEP, WHO, 1979

14 Kelce WR, Stone CR, Laws SC, Gray LE, Kemppainen JA, Wilson EM. Persistent DDT metabolite p,p'-DDE is a potent androgen receptor antagonist. Nature 1995; 375: $581-5$

15 Danzo B. Environmental xenobiotics may disrupt normal endocrine function by interfering with the binding of physiological ligands to steroid receptors and binding proteins. Environ Health Perspect 1997; 105: 294-301

16 Turusov V, Rakitsky V, Toamtis L. Dichlorodiphenyltrichloroethane (DDT): ubiquity, persistence, and risks. Environ Health Perspect 2002; 110: $125-8$

17 Hunter OJ, Hankinson SE, Latten F et al. Plasma organochlorine levels and the risk of breast cancer. $N$ Engl $J$ Med 1997; 337:12573-81

18 Agency for Toxic Substances and Disease Registry (ATSDR). Toxicological profile for DDT, DDE, DDD. 2002. Atlanta, GA: U.S. Department of Health and Human Services, Public Health Service. http://www.atsdr.cdc.gov/toxprofiles/tp35.html. Accessed Oct 2008.

19 Fry DM, Toone CK. DDT-induced feminization of gull embryos. Science 1981; 213: 93-5

20 Guillette LJ Jr, Woodward AR, Crain DA, Pickford DB, Rooney AA, Percival HF. Plasma steroid concentrations and male phallus size in juvenile alligators from seven Florida Lakes. Gen Comp Endocrinol 1999; 116: 356-72

21 Gray LE, Jr, Ostby LE, Furr $\mathrm{J}$ et al. Effects of environmental antiandrogens on reproductive development in experimental animals. Hum Reprod Update 2001; 7: 248-64

22 De Jager C, Farias P, Barazza-Villarreal A, Avilla $\mathrm{MH}$, Ayotte P, Dewailly E. et al. Breakthroughs in Andrology: reduced seminal parameters associated with environmental DDT exposure and p,p'-DDE concentrations in men in Chiapas, Mexico: a Cross-Sectional Study. J Androl 2006; 27: $16-27$

23 Aneck-Hahn NH, Schulenburg GW, Bornman MS, Farias $\mathrm{P}$, de Jager C. Impaired semen quality associated with environmental DDT exposure in young men living in a malaria area in the Limpopo Province, South Africa. $J$ Androl 2007; 28: 423-34

24 Medical Research Council of South Africa. Malaria in Southern Africa. Malaria Risk in Southern Africa. January 2007. Information provided by the Malaria Research Programme of the Medical Research Council, South Africa. Information available at: http://www.malaria.org.za/Malaria_Risk/Risk_Maps/risk_m aps.html. Accessed December 19, 2008.

25 Jordan GH, Schlossberg SM. Surgery of the penis and uethra. In Wein AJ eds. Campbell-Walsh Urology. $9^{\text {th }}$ edn. WB Saunders, Elsevier, 2007: 1089

26 Elder JS. Abnormalities of the genitalia in boys and their surgical management. In Wein AJ, eds. Campbell-Walsh Urology. $9^{\text {th }}$ edn. Saunders, Elsevier 2007: 3754-60

27 Longnecker MP, Klebanoff MA, Brock JW et al. Maternal serum level of 1,1-dichloro-2,2-bis(p-chlorophenyl) ethylene and risk of cryptorchidism, hypospadias, and polythelia among male offspring. Am J Epidemiol 2002; 155: 313-22

28 Damstra T, Barlow S, Bergman A, Kavlock R, Van Der Kraak G eds. Global Assessment of the State of the Science of Endocrine Disruptors. International Programme on Chemical Safety. Geneva: Switzerland. World Health Organization 2004 Available at http://www.who.int/ipcs/publications/new_issues/endocrine _disruptors/en/

29 Longnecker MP, Klebanoff MA, Dunson DB, Guo X, Zhou $\mathrm{H}$, Brock JW. Maternal serum level of the DDT metabolite DDE in relation to fetal loss in previous pregnancies. Environ Res 2005; 97: 127-33

30 Eskenazi B, Marks AR, Bradman A et al. In utero exposure to dichlorodiphenyltrichloroethane (DDT) and dichlorodiphenyldichloroethylene (DDE) and neurodevelopment among young Mexican American children. Sothoatrics 2006; 118: 233-41

31 Retik AB, Borer JG. Hypospadias. In Walsh PC, Retik AB, Vaughan ED Jr, Wein AJ eds. Campbell's Urology. $8^{\text {th }}$ edn. Philadelphia: WB Saunders 2002: 2284-333

32 Toppari J, Larsen JC, Christiansen $\mathrm{P}$ et al. Male reproductive health and environmental xenoestrogens. Environ Health Perspect 1996; 104 (Suppl. 4): 741-803

33 Delport SD, Christianson AL, van den Berg HJ, Wolmarans L, Gericke GS. Congenital anomalies in black South African liveborn neonates at an urban academic hospital. $S$ Afr Med J 1995; 85: 11-5

34 Venter PA, Christianson AL, Hutamo CM, Makhura MP, Gericke GS. Congenital anomalies in rural black South African neonates - a silent epidemic? S Afr Med J 1995; 85: 15-20

35 Hammond-Tooke D. Transformations on a theme. In Hammond-Tooke D ed. The Roots of Black South Africa. Johannesburg: Jonathan Ball Publishers, 1993: 1121

36 Consanguinity. Consanguineous marriage in Africa. Information available at http://www.consang.net/images/c/c8/Africa.pdf Accessed 21 December 2008

37 Longnecker MP, Gladen BC, Cupul-Uicab LE et al. In utero exposure to the antiandrogen 1,1-dichloro-2,2-bis (pchlorophenyl) ethylene (DDE) in relation to anogenital distance in male newborns from Chiapas, México. Am $J$ Epidemiol 2007; 165: 1015-22

38 Sharp B, Kleinschmidt I, Streat E et al. Seven years of regional malaria control collaboration - Mozambique, South Africa, and Swaziland. Am J Trop Med Hyg 2007; 76: 42-7

39 Van den Berg H. Global status of DDT and its alternatives for use in vector control to prevent disease. Stockholm Convention on Persistent Organic Pollutants. Stakeholders' Meeting to review the interim report for the establishment of a global partnership to develop alternatives to DDT. UNEP/POPS/DDTBP 23 October 2008; 1/2: 2008 
Information

available

at

http://chm.pops.int/Programmes/DDT/Meetings/BusinessPl

an/tabid/418/language/en-US/Default.aspx Accessed 23

October 2008

Correspondence: Riana Bornman, Department of Urology, University of Pretoria, PO Box 667, Pretoria 0001, Republic of South Africa.

e-mail: mbornman@medic.up.ac.za

\section{Abbreviations}

DDT

technical mixture of chiefly p,p'-DDT and o,p'-DDT

$o, p^{\prime}$-DDD

1,1-dichloro-2-(o-chlorophenyl)-2-( $p$-chlorophenyl) ethane

$p, p^{\prime}$-DDD

1,1-dichloro-2,2-bis(p-chlorophenyl) ethane

$o, p^{\prime}$-DDE

1,1-dichloro-2-(o-chlorophenyl)-2-( $p$-chlorophenyl) ethylene

$p, p^{\prime}$-DDE

1,1-dichloro-2,2-bis( $p$-chlorophenyl) ethylene

$o, p^{\prime}$-DDT

1,1,1-trichloro-2-(o-chlorophenyl)-2-(p-chlorophenyl) ethane

\section{$p, p^{\prime}$-DDT}

1,1,1-trichloro-2,2-bis( $p$-chlorophenyl) ethane

UGBD

external urogenital birth defect

IRS

indoor residual spraying

UDT

undescended testicle

TDS

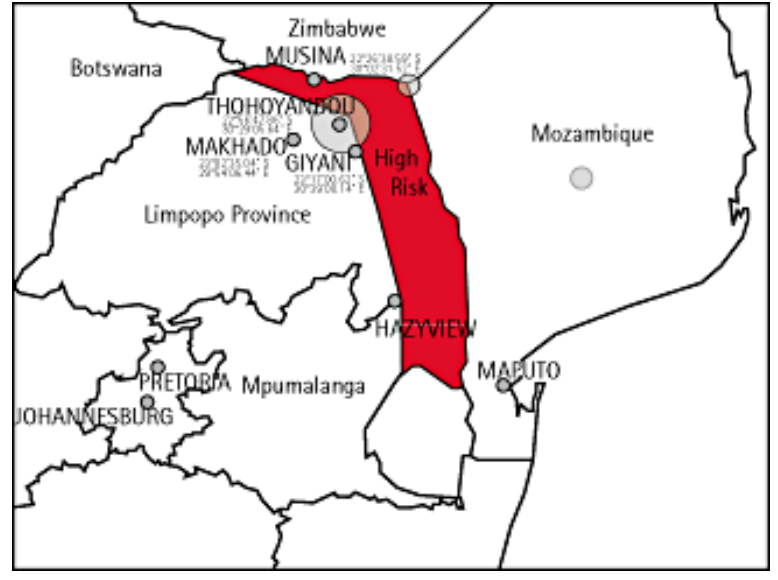

Fig. 1. Malarial risk areas in South Africa, with the Thohoyandou area indicated by the grey circle (adapted from MRC 2008 map). The picture also shows the neighbouring countries Zimbabwe, Mozambique and Botswana.

testicular dysgenesis syndrome. 
Table 1 General characteristics of 3310 newborn baby boys and their mothers by DDT exposure at Tshilidzini Hospital between May 2004 and May 2006

\begin{tabular}{lcc}
\hline $\begin{array}{l}\text { Mean (sD, range) } \\
\text { or n (\%) variable }\end{array}$ & Exposed & Unexposed \\
\hline Birth weight, kg & $3.23(0.45,2.5-5.1)$ & $3.20(0.4,2.5-4.7)$ \\
Number of siblings & $2.17(1.4,0-11)$ & $2.11(1.4,0-10)$ \\
Mother's: & & \\
age, years & $25.39(6.5,14-48)$ & $25.40(6.4,13-44)$ \\
duration living in village, years & $22.73(8.9,<1-44)$ & $22.68(9.0,<1-48)$ \\
Consanguinity & $84(3.5)$ & $36(3.9)$ \\
Maternal age, years & & \\
$\quad$ <20 & $204(8.5)$ & $51(5.6)$ \\
$\quad 20-34$ & $1988(83.1)$ & $792(85.8)$ \\
$\quad 35$ & $200(8.4)$ & $210(23.4)$ \\
Maternal occupation: & & $384(42.8)$ \\
$\quad$ Employed & $541(23.0)$ & $303(33.8)$ \\
Homemaker & $1027(43.6)$ & $842(92.1)$ \\
Student or scholar & $788(33.4)$ & $13(1.4)$ \\
Ethnicity: & & $34(3.8)$ \\
$\quad$ Venda & $2156(90.0)$ & $13(1.4)$ \\
Pedi & $42(1.8)$ & $12(1.3)$ \\
Tsonga & $164(6.8)$ &
\end{tabular}

Table 2 Distribution of maternal village history of DDT spraying in Limpopo Province, South Africa (3310)

\begin{tabular}{lrr} 
DDT sprayed, n (\%) & \multicolumn{1}{c}{ Yes } & \multicolumn{1}{c}{ No } \\
\hline Currently DDT exposed & $981(30)$ & $2329(70)$ \\
Village sprayed 1995-2003 & $738(22)$ & $2572(78)$ \\
Any DDT exposure & $2396(72)$ & $914(28)$ \\
\hline
\end{tabular}

Table 3 Distribution of UGBDs in newborn boys by indoor DDT spraying history

\begin{tabular}{lccc}
\hline Malformation & $\mathrm{n}(\%)$ & Ever sprayed & Never sprayed \\
\hline Micropenis & $71(2.2)$ & $53(2.2)$ & $18(2.0)$ \\
Cryptorchidism & $70(2.4)$ & $58(2.4)$ & $12(1.3)$ \\
Hypospadias & $171(5.6)$ & $122(5.1)$ & $49(5.4)$ \\
Chordee & $44(1.4)$ & $38(1.6)$ & $6(0.7)$ \\
Phimosis & $34(1.1)$ & $26(1.1)$ & $8(0.9)$ \\
Penile cyst & $7(0.27)$ & $3(0.1)$ & $4(0.4)$ \\
Any UGBD & $357(11.0)$ & $264(11.0)$ & $93(10.2)$ \\
\hline
\end{tabular}

Table 4 UGBDs in newborn boys significantly associated $(P \quad 0.15)$ with DDT exposure and other risk factors

\begin{tabular}{lll}
\hline UGBD & Predictor & Odds ratio (95\% CI) \\
\hline UDT & & \\
& Village ever sprayed & $2.1(1.14-3.92)$ \\
& Never sprayed (ref) & 1.0 \\
& Time lived in village, years & $0.96(0.94-0.99)$ \\
Occupation & & $2.4(1.15-4.94)$ \\
& Homemaker & $2.1(1.0-4.54)$ \\
& Student & 1.0 \\
Hypospadias & Employed (ref) & $1.6(0.84-3.0)$ \\
& Consanguinity & 1.0 \\
Chordee & No (ref) & $2.5(1.1-6.0)$ \\
& Village ever sprayed & 1.0 \\
Any UGBD & Never sprayed (ref) & $1.5(0.97-2.4)$
\end{tabular}


No (ref) 1.0

Time lived in village, years $\quad 0.99(0.98-1.0)$

Occupation

Homemaker $1.3(1.1-1.7)$

Employed or student (ref) $\quad 1.0$ 